\title{
IMPRESIONES Y RECUERDOS DE JULIO NOMBELA
}

\author{
$M^{\mathrm{a}}$ de los Ángeles AYALA \\ Universidad de Alicante
}

Santos Justo Nombela (1836-1919), conocido en el ámbito literario por el seudónimo de Julio Nombela', es un escritor de escasa proyección actual; sus obras apenas merecen unas escuetas líneas en los manuales de historia de la literatura del siglo XIX. Sin embargo, Nombela es el prototipo del escritor de la segunda mitad del siglo, del escritor de oficio, del literato que luchará tenaz e incansablemente por vivir exclusivamente del producto de sus obras. Azorín (1998, pág. 1049), atento observador, subrayaba a la altura de 1914, su inconfundible carácter de trabajador infatigable, indemne al desaliento. Un escritor que, sin ocupar nunca un puesto de extrema relevancia en el mundo de las letras, se nos revela como un novelista abierto a las demandas del público e introductor de novedades en las empresas periodísticas en las que participa.

' El propio Julio Nombela nos da la información relativa a este cambio de nombre. En sus Impresiones y Recuerdos rememora el preciso momento en el que don Pedro José de Peña, editor del Correo de la Moda, elige el nombre de Julio por su carácter eufónico: «En periódicos dedicados como el mío a señoras -me dijo- es necesario que las firmas despierten por la sonoridad de los nombres la simpatía de las lectoras. El apellido de usted me agrada, recuerda los italianos, que por lo general no carecen de poesía; pero el nombre... -no se ofenda usted por lo que le digo-, el nombre resulta vulgar, prosaico [...] si entre los que seguramente le pusieron a usted en la pila no hay otro de los que desde luego se apoderan del aprecio femenil, será preciso buscar un seudónimo.

Le indiqué los dos nombres que además de Santos había recibido en la pila bautismal; oyó mal el de Justo, se le figuró que había dicho Julio, y frotándose las manos exclamó:

-¡Magnífico! Julio Nombela; eso ya es otra cosa» (Nombela 1976, pág. 486). 
Cuando Julio Nombela escribe sus Impresiones y recuerdos (1909-1912) los libros de memorias se habían aclimatado en España después de la aparición de una copiosa producción a lo largo del siglo XIX (Caballé 1995; Durán López, 1997). Algunos de los hombres más célebres del siglo escriben relatos de claro sabor autobiográfico motivados por las más variadas razones; desde la esperanza de justificar una determinada postura política-Memorias Críticas y Apologéticas de Manuel Godoy-o religiosa -The Life od the Reverend Joseph Blanco White, Written by himself-, hasta el deseo de inmortalizar literariamente un tiempo y una sociedad que ha dejado de existir -Memorias de un setentón de Mesonero Romanos-. Sobre estas razones se sobrepone, claro está, el inconfesable o explícito deseo de que el lector reconozca la propia valía del protagonista de esas confesiones. Este objetivo es, sin duda, el que persigue Julio Nombela, pues en el transcurso del relato mostrará con orgullo los principales hitos de su carrera profesional. Así, a lo largo de más de mil páginas el protagonista de estas memorias se proyecta como un hombre que luchando contra todo tipo de obstáculos llega a convertirse en uno de los escasísimos escritores que en el siglo XIX pudo vivir exclusivamente del producto de las letras. Nombela, consciente de que difícilmente su ortodoxa biografía - «No hay en la historia [...] de mi vida nada de sorprendente, de extraordinario ni de trágico [...]» (pág. 1061)- pueda despertar el interés de algún editor, se apresura a dejar testimonio de su vida. Nombela, que conoce muy bien el género ${ }^{2}$, sabe que el relato autobiográfico le permite no sólo hacer reflexionar al lector sobre su propia trayectoria profesional, sino también comprender y juzgar su lucha por abrirse camino en un tiempo histórico y una sociedad pretérita que el lector de 1909 desconoce. Dos coordenadas, lo autobiográfico y lo memorialístico, que Nombela amalgama con total perfección en sus Impresiones y Recuerdos.

Nombela inicia su autobiografía rememorando los años de infancia y de adolescencia, etapas importantísimas en la vida del hombre y en las que, según el escritor, se marcan de manera indeleble los rasgos más personales $-\ll$ No faltarán en el transcurso de mi relato ocasiones de demostrar cuánto han influido en mi modo de pensar y de ser [...] las impresiones que en mi niñez y adolescencia fueron educando mi inteligencia, despertando mis sentimientos y formando mi carácter» (pág. 66)-. Nombela, con clara conciencia de su propia individualidad, acumula en estas primeras páginas esas experiencias y anécdotas vividas que expliquen los principios que rigen su vida adulta. Así, el amor a la familia, la

2 Julio Nombela conocía muy bien las biografías y las memorias, ya que a lo largo de su labor periodística había escrito biografías de personajes históricos y contemporáneos en diversas ocasiones -San Ignacio, Hernán Cortés, Cristóbal Colón, Barbieri, Arrieta, Fernández y González-. Asimismo había realizado la traducción de las Memorias de Garibaldi para la Casa Garnier. 
voluntad, la laboriosidad, la modestia, la incansable búsqueda de la justicia, su independencia y sus firmes creencias religiosas serán los valores adquiridos o transmitidos por sus familiares más cercanos.

De estos primeros años Nombela destaca su carácter impresionable y su desbordada imaginación. Igualmente subraya su escasa afición al estudio, pues ni siquiera la lectura le apasiona hasta descubrir El conde de Montecristo. Ni la escuela ni el Instituto le ofrecen el menor atractivo. De hecho confiesa no haber alcanzado el grado de bachiller, pues «los cuatro años que cursé fueron un verdadero desierto en el que sólo me ofrecieron pequeños oasis algunas lecciones de Retórica y Poética y algunos episodios de la historia universal» (pág. 86). Esta falta de aplicación en los estudios la justifica Nombela por su temprana vocación teatral, una afición que se retrotrae a estos años infantiles y que se recrudece a partir de 1848, fecha en la que finalmente abandona el Instituto. El escritor rememora detalladamente el momento en que decide firmemente convertirse en actor, cuando su padre, como premio a su destacada interpretación de un fragmento de El trovador de García Gutiérrez en una celebración escolar, le lleva al teatro de la Cruz donde se representa, precisamente, dicha obra. Nombela transmite con total vivacidad, a pesar del tiempo transcurrido, las impresiones que experimentó en su primer contacto con el espectáculo teatral ${ }^{3}$.

Nombela, que no pertenece a una familia de actores, recurre a otro de los caminos tradicionales de la época para satisfacer su aspiración de consagrarse al teatro: las representaciones caseras. Dirigirá un teatro casero durante la estancia de su familia en Morón de la Frontera (1849). En un rudimentario e improvisado teatro Nombela y sus amigos representarán algunas comedias del género andaluz, que por entonces estaban en boga-La flor de la canela, El tío Caniyitas, El corazón de un bandido, Diego Corrientes-, el indispensable Puñal del godo o comedias costumbristas donde se censura, por ejemplo, la venta de bienes eclesiásticos - Las elecciones de un pueblo-. Tras un año en Morón la familia regresa a Madrid y Nombela entra a formar parte de una asociación de aficionados que tenía alquilado el teatro del Genio. Asimismo da cumplidas noticias sobre el auge del teatro

${ }^{3}$ Nombela las describe de la siguiente manera: «No se ha borrado de mi mente la impresión que me causaron la sala con sus palcos, sus lunetas, sus galerías llenas de gente; la gran araña que pendía del techo; el telón que ocultaba algo que no podía adivinar [...] Después, cuando se levantó el telón, no apartaba mis ojos del escenario, oía con avidez sin comprender lo que oía, y ante aquel cuadro magnífico que no había podido ni siquiera soñar, me olvidé por completo del objeto que en primer término me había incitado a ir al teatro, y sin explicarme lo que veía, lo que oía, admiré, como mi alma podía admirar entonces, el teatro, ese grandioso cuadro donde el arte reúne y combina todos sus elementos, todos sus encantos, todas sus bellezas; y sorprendido, asombrado, supuse con mi infantil inexperiencia que nada había en el mundo superior al actor» (pág. 52) 
casero en estas fechas, relatando su participación en las representaciones que a partir de 1851 se celebran en el magnífico teatro que el escultor Ponciano Ponzano construyó en su domicilio particular (págs. 1332-137). Estas actividades las compagina con la asistencia regular a las clases de declamación del Conservatorio, institución en la que se matricula cuando todavía no ha cumplido catorce años. Es allí donde conocerá a Carlos Latorre y José García Luna, los dos célebres actores encargados de impartir la docencia. El primero, centrado en la tragedia y el drama; el segundo, en la comedia y el melodrama. Nombela ofrece datos precisos sobre las obras de mayor éxito - Sancho García, Los amantes de Teruel, El puñal del godo, El trovador, entre los dramas; las tragedias Pelayo y Otelo y las comedias de Moratín, Bretón de los Herreros, Ventura de la Vega, Moliere y Scribe-. Traza, igualmente, unos exhaustivos retratos de sus dos maestros, recrea el ambiente que reinaba en aquellas clases de declamación y habla de sus compañeros, destacando a Pepita Hinojosa, la única condiscípula que adquirió notoriedad en la escena, y a José Campo y Navas y Eduardo del Palacio que triunfaron en el ámbito periodístico. La visión del escritor se impone a la del personaje del relato, pues aunque consigue comunicar las impresiones que al joven le produce este acercamiento al mundo teatral, Nombela, desde la perspectiva que ofrecen los años, subraya la deficiente preparación que las clases de declamación ofrecían a los matriculados, pues aunque expresa su admiración por el trabajo de García Luna y Latorre sobre los escenarios, también subraya su escaso acierto a la hora de transmitir enseñanzas, ya que «los dos primeros profesores se limitaron a convertir el aula en una sucursal del escenario» (pág. 102).

Nombela, acuciado por la necesidad de contribuir con su trabajo al exiguo bienestar familiar e impaciente por hacerse un hueco en la escena, logra entrar como racionero en la compañía de Joaquín Arjona gracias a una recomendación de Bretón de los Herreros. Pese a los escrúpulos de su familia ${ }^{4}$ el escritor logra de esta manera iniciar su camino como actor profesional. Allí conocerá a algunos de los actores y actrices más célebres de la época, de los que ofrecerá el oportuno retrato -Teodora Lamadrid, Concepción Ruiz, María Rodríguez, Manuel Ossorio, Fernando Ossorio, Fabiani, Cristina Ossorio, etc.-. Nombela, a la vez que relata sus vivencias, describe el teatro por dentro; da cuenta de cómo se efectúa el

${ }^{4}$ Nombela recoge en su autobiografía la generalizada opinión negativa que sobre las gentes del teatro se tiene en la época. Así, cuando en su autobiografía relata su decisión de dedicarse a la escena, señala lo siguiente: «Me guardé bien de confiar a mis padres mi propósito, porque siempre que en la intimidad de la familia o en la conversación con los amigos se tocaba ese tema, todos hablaban mal de los cómicos, calificándolos de holgazanes y viciosos y repetían que la Iglesia los rechazaba y que la buena sociedad no los admitía en su seno» (pág. 84). 
reparto de papeles dentro de la compañía o de qué modo se desarrollan los ensayos de las obras que inauguran la temporada de 1851 del Teatro del Drama ${ }^{5}$, Escuela de maridos de Molière y la comedia corta La apuesta.

Su experiencia como actor concluye a principios de 1853, después de trabajar dos temporadas en la compañía de Arjona, el contacto directo con el mundo teatral le desilusiona. Nombela tiene un alto concepto del mismo, pues como el propio autor señala «el teatro no se limitaba a ser un recreo, un esparcimiento del ánimo, una diversión, sino como algunos autores han afirmado, escuela de costumbres, espejo de la vida y además, según mi inexperta pero firme opinión, el conjunto en un solo foco de todos los resplandores de las bellas artes, y por lo tanto, educador del sentimiento, poderoso elemento de cultura, gloria de la nación» (pág. 181). Nombela convencido, no olvidemos que sólo tiene dieciséis años, de que desde su humilde posición no puede contribuir a mejorar las condiciones íntimas en que el teatro vive, se decanta hacia el estudio, proyectando la redacción de una Historia universal del teatro que pusiese de manifiesto las excelencias de este arte. Este alejamiento es sólo momentáneo, pues el teatro siempre aparece vinculado a su labor periodística y a su labor creativa. Lo que le permite seguir emitiendo sus personales puntos de vista sobre intérpretes, impresores y autores dramáticos que se sucedieron en los escenarios españoles.

Si interesantes son los datos que Nombela aporta sobre el mundo del teatro, no menos relevantes son sus vivencias y reflexiones en torno al periodismo de la época. Nombela, decepcionado del teatro, vuelca en el periodo que comprende desde 1854 a 1860 todos sus esfuerzos hacia el periodismo en búsqueda de un trabajo digno y satisfactorio y de una posición económica estable. Tras la aventura de fundar $E l M u n d o^{6}$ Nombela entra a formar parte de la redacción de $E l$

${ }^{5}$ Nombela nos ofrece los siguientes datos al respecto: «A continuación hizo el reparto de papeles, confiando el de doña Rosa a Teodora Lamadrid, a quien atribuyó los mayores elogios con el asentimiento de cuantos le oíamos; el de doña Leonor, a Concepción Ruiz; el de Julina, a María Rodríguez; el de don Manuel, a su hermano; el de don Enrique, a Manuel Ossorio; el de Cosme, a Nogueras, encargándose él del de don Gregorio [Joaquín Arjona]. Los del Comisario y el Escribano quedaron a cargo de dos partes de por medio: José Alisedo, concienzudo actor y excelente persona, de quien fui muy amigo, y un tal Bermonet.

' El Mundo, fundado por Bécquer, García Luna, Javier Maíquez y el propio Nombela, tuvo una aparición fugaz, pues sólo se llegó a imprimir un número de este periódico literario. Nombela da cuenta de la suerte que corrió el periódico por la falta de experiencia de sus redactores y fundadores: «E] periódico sería semanal y se titularía $E l M u n d o$. Bécquer fue el padrino y escribió un preciso artículo-programa [...] El primer número de El Mundo apareció con el artículo indicado, otro de Luna, otro mío y poesías de los cuatro únicos redactores; pero olvidamos que era necesaria una administración para hacer la indispensable propaganda, y los miles de ejemplares que se tiraron en buen papel y hasta con lujo tipográfico, no fueron admitidos en las librerías en comisión para su venta» (pág. 371). 
Porvenir, cuyo propietario y director era el progresista Juan Belza ${ }^{7}$. El escritor se hará cargo de la gacetilla, una de las secciones más populares por aquel entonces de los periódicos. También como gacetillero encuentra acomodo en Las Cortes, periódico dirigido por su propietario, don Camilo Alonso Valdespino y secundado por José Emilio Santos, Enrique Hernández, José María Larrea y Eugenio Olavarría. Tras un peregrinaje en búsqueda de nuevas colaboraciones en periódicos tan dispares como El Clamor Público, La Iberia o La Esperanza, Nombela entra como redactor en 1856 en el prestigioso e influyente Diario Español donde permanecerá dos años y medio encargándose de las revistas de teatros, de la gacetilla y del folletín ${ }^{8}$. Este periodo es el más importante en lo que respecta a su formación periodística, pues cuando la dirección del mismo pasa de manos de Manuel Rancés y Villanueva a las de Mariano López Roberts, éste refuerza la redacción con el acreditado periodista y taquígrafo del Congreso don Francisco de Paula Medrano, quien se convertirá en el maestro que descubra a Nombela los entresijos de su nueva profesión. Ya con el pseudónimo de Julio Nombela recorre las redacciones del Correo de la Moda, La España Musical y Salones y Teatros, Periódico para todos, El Correo de Ultramar, colaborando esporádicamente. A finales de 1858 aparece su firma en El Fénix del marqués de Remisa, claro partidario de doña María Cristina. Sus colaboraciones concluyen a finales de enero de 1859 , cuando el periódico desaparece por cuestiones políticas de forma repentina. Sus redactores? fundarán El Conciliador que, tras tres o cuatro meses de vida, desaparece, igualmente, dejando paso al Horizonte. Nombela colabora con artículos literarios en ambos periódicos hasta que, harto de las intrigas políticas que se

${ }^{7}$ Cuando el periódico se funda la redacción está integrada por el propio director, que escribiría los artículos de fondo; un joven poeta alicantino, Carlos Navarro y Rodrigo; Juan Antonio Viedma, poeta discípulo de Zorrilla y el trío formado por Nombela, Bécquer y García Luna. Navarro y Viedma que ayudarían a Belza a escribir los artículos doctrinales percibirán un sueldo de treinta duros mensuales, mientras que Luna -sueltos políticos-, Bécquer -artículos literarios y revistas de teatros- y Nombela -las gacetillas-, percibirán sólo veinte duros al mes.

* Nombela señala que «el Diario Español era un periódico batallador, había hecho una terrible campaña contra Espartero y sus adictos y a favor de la política de O'Donnell; era liberal-conservador y no se distinguía por lo esmerado de su confección. Lo principal en él eran los intencionados artículos de fondo de [Juan de] Lorenzana y las valientes polémicas que sostenía Rancés. Inspiraban la política del Diario los hermanos Concha, principalmente don José, y también influían en su actitud don Alejandro Mon, don Antonio Ríos Rosas[...]» (pág. 466). Nombela señala que cuando él entra en la redacción el Diario Español se había convertido en un periódico ministerial que se limitaba a aplaudir al Gobierno hiciera lo que hiciera y a defenderle de sus enemigos.

"La dirección de El Fénix recaía en Juan Valero y Soto y entre sus redactores se contaba con las firmas de Baltasar Anduaga y Espinosa que procedía del Heraldo del conde de San Luis; un joven abogado, don Sebastián Fuente Alcázar, Joaquín Pérez Comoto, y García Luna que se encargaba de la confección del periódico y los sueltos periódicos. También colaboraban habitualmente el vizconde de San Javier y Juanito Valero de Tormos. 
urden desde las páginas de la prensa, decide alejarse de la redacción de $E l$ Horizonte para fundar su propio periódico semanal, Las Letras y las Artes, donde la independencia de opinión sería premisa fundamental. Este periódico, tras alcanzar un cierto éxito, desaparecerá después de seis meses de vida.

Nombela a la hora de comentar sus primeros pasos por las redacciones de los periódicos anteriormente señalados suele seguir una misma pauta. Así se detiene en ofrecer datos sobre propiedad, dirección, integrantes de la redacción y tareas encomendadas a cada uno de ellos, remuneración, tendencia política, anécdotas significativas, sin olvidar incluir retratos pormenorizados de los principales periodistas de la época. Asimismo Nombela, en diversos momentos, realiza comentarios sobre periódicos en los que no participa directamente, pero cuya relevancia en la época es indiscutible, como sucede, por ejemplo, en las páginas dedicadas a destacar la importancia de La Correspondencia de España. De los datos aportados en estos primeros capítulos dedicados al periodismo destaca la información suministrada sobre las remuneraciones de los periodistas. Según Nombela los sueldos oscilan entre los treinta y los veinte duros mensuales, dependiendo de que su tarea se dirija a confeccionar los artículos de fondo o doctrinales o a configurar las revistas musicales, de teatro o las célebres gacetillas $^{10}$, tareas, éstas últimas, que solían desempeñar los periodistas de menor experiencia. Nombela señala que percibió veinte duros en El Porvenir, veinticinco en Las Cortes y que llegó a cobrar treinta duros mensuales cuando entró en la redacción del Fénix.

La proliferación de periódicos en esta época lleva aparejada la frecuente dificultad de atraer a un número elevando de lectores, de ahí que los periódicos aparezcan y desaparezca en escaso periodo de tiempo. Alcanzar la cifra de cuatro mil suscriptores se considera un auténtico éxito editorial, así que contar con «quince mil, veinte mil, treinta mil, como contó la Correspondencia de España a los tres o cuatro meses de su fundación, se consideró un verdadero prodigio» (pág. 466). Un éxito sólo superado, según el escritor, por El Español, el periódico fundado y dirigido por Andrés Borrego.

10 Julio Nombela al comentar su tarea como cronista de salones subraya las innumerables muestras de afecto que le dirigen actores, autores, cantantes, dueños de restaurantes elegantes, comerciantes y las familias de buen tono que desean ver reproducidas en las páginas del periódico la suntuosa y espléndida fiesta celebrada en su residencia la noche anterior. Nombela desconfía de tales demostraciones de afecto interesado y relata el caso de un periodista italiano afincado en España. Pascual Cataldi, que sin ningún tipo de rubor emitía elogios o agrias censuras dependiendo de la cuantía que el artista destinaba a subvencionar su propio periódico. Nombela incluye este caso para subrayar la sinceridad y gratuidad de los elogios emitidos por los cinco o seis periodistas que en aquel tiempo compartían la redacción de las revistas de sálones en distintas publicaciones. 
Nombela también subraya el carácter político y partidista de los periódicos de mediados de siglo. Así, por ejemplo, afirma que El Porvenir se fundó con el exclusivo objetivo de combatir a un rico liberal-conservador que había entrado en el ministerio de Hacienda, don Juan Bruil. Su experiencia en El Diario Español - «el más batallador, y por consiguiente, el más leído y celebrado de los periódicos que entonces influían en la política» (pág. 464)- refuerza sus primeras impresiones. El Diario Español había contribuido al triunfo de O'Donnell y sus redactores alcanzan puestos políticos de relieve como justo premio a su campaña contra Espartero". Nombela subraya la influencia que la política ejerce sobre los periódicos al comentar las frecuentes controversias y polémicas que se desatan en las publicaciones de distinto signo, unos enfrentamientos verbales que, en ocasiones, se dirimen en duelos protagonizados por periodistas de distintos medios. Para corroborar la veracidad de sus afirmaciones Nombela relata cómo poco antes de que abandonara la redacción del Diario Español en 1858, los redactores políticos del mismo sostenían una fuerte disputa con La Iberia -órgano del ala progresista-, confrontación que dio lugar a un desafío entre su compañero de redacción Maldonado Macanaz y Calvo Asensio, periodista de La Iberia. Estos duelos fueron tan frecuentes en la época que no era raro que los directores contratasen a un maestro de armas con el fin de adiestrar a los miembros del periódico, como sucedió mientras él permaneció en la redacción del Diario Español (págs. 489-492). Este marcado acento político de los propietarios, directores y periodistas en general se deja sentir, evidentemente, en el capítulo económico. Así Nombela señala que mientras los periodistas se encuentran en la oposición, el periódico vive del producto de las suscripciones de amigos y correligionarios. Cuando el partido apoyado alcanza el poder, las subvenciones del Gobierno o de los banqueros, que se aseguran de esta forma posteriores favores, contribuyen a su sostenimiento. Es, precisamente, esta clara interferencia entre política y periodismo lo que aleja a Nombela de El Horizonte y lo que le lleva a emprender su fructífero viaje a París ${ }^{12}$. La visión que sobre el periodismo de esta época transmite Nombela se completa con la galería de retratos que incluye en estas páginas:

"Julio Nombela señala que cuando O'Donnell llega al poder «los redactores del Diario Español obtuvieron puestos importantes: Rancés fue nombrado ministro plenipotenciario de España en el entonces imperio del Brasil; Lorenzana desempeñó un alto cargo en Gobernación; Ností, el administrador del periódico, fue empleado en el Ministerio de Hacienda, y los demás auxiliares obtuvieron también su parte alícuota en el festín del presupuesto» (pág. 466).

${ }^{12}$ La opinión que Nombela tiene de la política es harto elocuente: «La política no tiene entrañas: es egoísta, codiciosa, convierte por conveniencia las iniquidades en sacrificios pseudopatrióticos, todo lo supedita al logro de sus ambiciones, Qua nominor leo es su moral y su divisa, y anticipándose a Darwin, desde los tiempos más remotos ha hecho, hace y hará de su superioridad convencional el arma con que destruye a los enemigos inferiores que la condenan y maldicen» (pág. 448). 
Emilio Santos (pág. 420), Enrique Hernández (pág. 421), José María Larrea (pág. 422), Eugenio de Olavarría (págs. 422 y 426), Alonso Valdespino (pág. 426), Francisco de Paula Madrazo (pág. 467), Zacarías Carvajal (págs. 467-468) Isidoro Autrán (pág. 468), Maldonado Macanaz (pág. 468), Flòrencio Moreno Godínez (pág. 492), Luis Rivera (pág. 493), etc.

Desde junio de 1860 a mediados de 1863 Nombela se instala en París buscando un ambiente cultural más propicio para dedicarse exclusivamente a tareas literarias y alcanzar, así, el aprecio del público y el sustento necesario para ayudar económicamente a su familia. No obstante, Nombela tiene buen cuidado en señalar a los lectores de su autobiografía que lo conseguido con tanto esfuerzo hasta este momento -el escritor tiene veintitrés años- no es desdeñable: «Había colaborado en periódicos importantes, publicado dos novelas, escrito un drama que rechazó Arjona sin haberle leído, convertido con Bécquer y Luna en obra dramática la novela Victor Hugo Nuestra Señora de París, hilvanado una zarzuela que puso en música Zabalda y juzgó Arrieta digna de la escena» (pág. 563). Nombela se siente orgulloso de lo llevado a cabo, aunque no constituyan éxitos de público o crítica. Esta autocomplacencia en su trabajo aflora en numerosos capítulos, pues Nombela, no olvidemos, persigue en todo momento que sus lectores perciban cómo el protagonista de sus Recuerdos luchó tenazmente, a menudo en condiciones adversas, hasta alcanzar el reconocimiento del público. París le es favorable, ya que las casas editoriales que publican una sección de libros españoles aceptan sus trabajos. La casa Garnier Hermanos publica sus novelas Las horas de recreo y Una mujer muerta en vida y varias traducciones, entre las que destaca Las Memorias de Garibaldi ${ }^{13}$. La prestigiosa editorial Hachette le encarga a su vez la versión española del periódico semanal Le Tour du Monde, mientras que desde España José Bravo y Destuet lo nombra corresponsal en París de La Correspondencia de España y Adelardo de Carlos le encarga una revista mensual para $L a$ Moda, periódico que publica en Cádiz. Nombela compagina estos trabajos con otro de los motivos que han impulsado su estancia en Francia: contribuir mediante el estudio del teatro francés y de las instituciones que salvaguardan su esencia a mejorar el decaído teatro español. Objetivo que lleva a cabo gracias a don Alejandro Mon, embajador de España en estos años. Nombela con enorme interés estudiará la organización del Conservatorio de Música y Declamación de París con la esperanza, fallida, de que estos estudios le permitan alcanzar una cátedra de teatro en su proyectado regreso a España.

${ }^{13}$ Nombela ofrece, también en esta ocasión, datos sobre sus remuneraciones: 200 frs. por la primera novela y 300 por la segunda; 250 frs. por las Memorias. Asimismo al hablar de la traducción de la Historia del consulado y del Imperio de Thiers señala que le pagaban 25 frs. por cada pliego de dieciséis hojas. 
Los años que transcurren desde principios de 1864 a 1873 constituyen para el escritor «la época más dichosa de mi vida pública» (pág. 704). Al regresar a Madrid Ríos Rosas le propone fundar y dirigir un periódico - El Fomento de España- que pretendía «fomentar la moral, la cultura y la riqueza de España» (pág. 745). Trabaja como redactor literario para La Época, La Política y La Patria. Publica sus novelas El bello ideal del matrimonio y El coche del diablo. Traduce novelas de Paul de Kock y triunfa como novelista por entregas cuando los hermanos Manini y el editor catalán Salvador Manero recurren a él para hacer frente a la creciente demanda de este género de novelas. Nombela da cuenta de los principales editores -Gaspar y Roig, Manini, Manero, Guijarro- y escritores -Fernández y González, Pérez Escrich, Ortega y Frías, Tárrega y Mateos- que en esta década convirtieron la literatura en un ventajoso negocio. Los datos son abrumadores al respecto, desde remuneraciones a novelistas hasta descripciones pormenorizadas de la forma de realización de dichas obras. A este respecto cabe destacar la determinante influencia del editor, pues en él recaía la elección del título y del asunto de la primera entrega, imponiendo su opinión sobre las preferencias del propio escritor. Comenta los leoninos contratos que autorizan al editor a suplir, ante cualquier eventualidad, al autor de la obra, encargando el reparto a otro escritor. Esta cláusula explica el conocido episodio en el que Nombela sustituye a Fernández y González cuando de forma repentina abandona Madrid en septiembre de 1867 tras haberse publicado dieciséis entregas de su novela $L a$ Virgen de la Paloma. Julio Nombela confiesa que esta práctica era bastante habitual y que él contó con la colaboración de otros escritores para poder cumplir sus compromisos. García Cuevas escribió algunos capítulos de las novelas tituladas Mendigos y ladrones, Pepe-Hillo, su obra histórica Los ministros en España y la continuación de la novela de Espronceda Sancho Saldaña. Para su novela San Ignacio de Loyola se auxilió de Martín Melgar y para las obras La bandera española y Dios, patria y rey contó con la inestimable ayuda de su amigo Juan Cancio Mena.

Nombela señala que a partir de la revolución del 68 la novela por entrega decae como consecuencia de los agitados acontecimientos políticos que vive la sociedad española. Desde 1865 a 1872, fecha en la que abandona definitivamente el género, Nombela dicta Los 300.000 duros y Un odio a muerte, para el editor Salvador Manero; Cristóbal Colón, Hernán Cortés, El país del oro, Mendigos y ladrones, La fiebre de riquezas e Ignacio de Loyola, para Urbano Manini; Pepe-Hillo, Los ministros en España y la ampliación del Sancho Saldaña de Espronceda, para Castro y Cerbó; para Labajos, La bandera española y para Gregorio Estrada el libro Dios, patria y rey. «Treinta tomos en 4.1 de 700 a 800 páginas cada uno, o sea, de 240 a 250.000 páginas, labor que me habría sido 
imposible realizar sin el auxilio de la taquigrafía» (pág. 709). Nombela subraya enfáticamente que él fue el primer escritor que en aras de obtener mayores beneficios económicos abandonó la práctica habitual de dictar las entregas a escribientes, utilizando para este fin los servicios del taquígrafo José Gutiérrez, innovación que le da un excelente resultado, ya que «[... pude aceptar mayor cantidad de trabajo, y en una hora, a lo sumo hora y media, dictaba tres entregas, o sea, veinticuatro páginas, lo que me proporcionaba de quince a dieciocho duros diarios y además me permitía atender a mis tareas periodísticas» (pág. 709).

En este periodo tan ponderado en Impresiones y Recuerdos Nombela pondrá en práctica algunas enseñanzas adquiridas durante su estancia en Francia. Así, por ejemplo, señala que al hacerse cargo de las crónicas mundanas de La Época tendrá en cuenta el estilo de las Croniques que publicaban los periódicos franceses. Aunque Nombela reconoce que Larra y Mesonero contribuyeron decisivamente al desarrollo del género, señala que escritores como Henri de Pene, Pierre Veron, Jules Noriac y Aurelien Scholl se convirtieron en los modelos que tanto él como otros periodistas que cubrían esta misma sección en diferentes periódicos -Pedro Antonio de Alarcón, Eusebio Blasco, Agustín Bonnat, Francisco de Acuña, Salvador López Guijarro- tuvieron presente para agradar a sus lectores en un género de difícil ejecución, pues debían hermanar el ingenio, la sinceridad, la malicia y la ligereza para hacer atractivos asuntos de efímera existencia. Bajo el rótulo de Misterios de Madrid Julio Nombela comenta en La Época «cuanto de novelesco, curioso, sensacional y divertido acontecía en la Villa y Corte» (pág. 749). Para este mismo periódico escribió una novedosa serie de biografías novelescas de personajes contemporáneos -Ayala, Barbieri, Arrieta, Fernández y González- y que aparecieron en una sección denominada Retratos a pluma. En esta ocasión el autor imitado es Eugenio de Mirecourt, periodista que se había hecho célebre en París precisamente por la publicación de estas biografías. Nombela tiene, sin embargo, buen cuidado a marcar las distancias entre ellos, pues mientras que él prefiere resaltar lo bueno y lo bello de los personajes, Mirecourt, además de señalar los méritos, revelaba las debilidades de sus biografiados, acercándose peligrosamente, en ocasiones, al libelo.

A principios de 1868 Nombela se propone, a semejanza de la conocida Gens de Lettres de París, una Sociedad de Autores. El proyecto era difícil, porque eran muy escasos los que vivían exclusivamente de las letras y «más escasos los bien avenidos» (pág. 772). Su iniciativa, sin embargo, tuvo éxito y el 16 de febrero de este año se celebró en el salón de actos del Ateneo su primera sesión ${ }^{14}$. La

\footnotetext{
${ }^{14}$ Nombela revela algunos datos que subrayan su satisfacción ante el éxito de la convocatoria. Señala que se distribuyeron doscientas invitaciones y que acudieron al acto ciento diecisiete escrito-
} 
Comisión encargada -Patricio de la Escosura, Luis María Pastor, Cayetano Rosell, Juan Eugenio Hartzenbusch, Ventura Ruiz Aguilera, Laureano Figueroa y el propio Nombela- llevó a cabo la elaboración de los estatutos y tras su aprobación se decidió elegir la indispensable junta de gobierno. Nombela señala que a partir de este instante la política injirió en el seno de aquella asociación exclusivamente literaria y la hizo inoperante.

Nombela, como muchos de sus contemporáneos, se ilusiona con el triunfo de La Gloriosa, pues entre los revolucionarios triunfantes había hombres inteligentes, enérgicos, honrados y competentes capaces de impulsarla, destacando en este sentido a Prim, Pi Margall, Ruiz Zorrilla, Salmerón y Topete. Nombela se asocia con Carlos Frontaura para fundar La Cosa Publica y el 26 de noviembre de 1868 aparece su primer número. La revista partía de la base de la total aceptación de la revolución triunfante en lo que respecta a los ideales de justicia, progreso, cultura, libertad. Unos principios que eran objeto de escenas, diálogos o monólogos en los que de un modo práctico se explicaba su significado. El éxito de La Cosa Publica se debió a «la sinceridad con que elogiábamos lo bueno y censurábamos lo malo, y sobre todo la independencia que reflejaban nuestros escritos» (pág. 778). La revista se publicó desde el 26 de noviembre de 1868 hasta finales de junio de 1870, siendo la causa de desaparición las diferencias entre Frontaura y Nombela a la hora de juzgar las candidaturas de los aspirantes a monarca. Vendieron el periódico a Antonio Mantilla, director de La Política, por la cantidad de treinta mil reales.

Defraudadas sus expectativas políticas por el rumbo de los acontecimientos Nombela decide, una vez más, dedicarse exclusivamente a las tareas literarias participando en un nuevo proyecto: La Ilustración Española y Americana. El gaditano Adelardo de Carlos que había transformado su microscópico periódico La Moda en la acreditada Moda Elegante quiso fundar en Madrid una Ilustración mejor que la que algunos años antes había publicado Fernández de los Ríos. Para llevar a cabo la empresa encargó a Nombela comprar la propiedad del Museo Universal, la revista ilustrada de Gaspar y Roig, que se convirtió, a partir de este momento, en La Ilustración Española y Americana. En Nombela recayó también

res y ochenta enviaron su adhesión. Entre los asistentes destaca nombres como Cayetano Rosell, Antonio Hurtado, José Castro y Serrano, Eduardo Gasset, Ruiz Aguilera, Bécquer, Eduardo Bustillo, González Bravo, Labra, Figueroa, Patricio de la Escosura, García Nieto, Ignacio Escobar, Ros de Olano, Frontaura, Francisco de Paula Madrazo, Campoamor, Sánchez Pérez, Segismundo Moret, Chico de Guzmán, Luis Rivera, entre otros. Asimismo enumera algunos de los autores de mayor notoriedad que se adhirieron al proyecto: el conde de San Luis, Cánvas del Castillo, Manuel Silvela, el marqués de Molins, el de Miraflores, el de Morante, Valera, Ayala, Hartzenbusch, Amador de los Ríos, Núñez de Arce, Bretón de los Herreros, Eusebio Blasco y Giner de los Ríos (págs. 771-774). 
la organización de la redacción del periódico y la obligación de escribir, a cambio de treinta duros mensuales, un artículo que saldría en la primera página. La desavenencia entre el propietario y el escritor se produjo a raíz de la participación del escritor Castro y Serrano en la revista, pues «con su habilidad para tirar la piedra y esconder la mano, siempre afectuoso conmigo, celebrando cuanto yo hacía, fue minándome el terreno para quedarse dueño del campo» (pág. 781). Castro y Serrano, según Nombela, convenció al editor de que a La Ilustración no le favorecía que ningún colaborador escribiese novelas por entregas. Nombela no accederá ni a dejar de escribirlas ni a utilizar un pseudónimo para firmar sus trabajos.

Entre 1870 y 1874 Nombela funda sucesivamente cinco revistas semanales y un periódico diario. En enero de 1870 Juan Cancio Mena y Nombela emprenden la publicación del semanario ilustrado consagrado a la propagación y defensa del régimen foral, El País Vasco-Navarro. A éste le sucederá en abril de 1871 La Nueva España, que adoptará una línea editorial más combativa ante la situación política. Esta última publicación sólo duró tres meses escasos, la misma duración que permaneció en circulación La Carta Blanca. Esta nueva revista se publicaba de forma anónima, pues Nombela temía la intervención de los seguidores de Ducazal, los temidos miembros de la partida de la porra. El 7 de marzo de 1873 Nombela en colaboración con Manuel Fraga y otros individuos que provenían del comercio madrileño edita La Gaceta_Popular. Nombela en el prospecto que se repartió antes de que apareciese el periódico proclama el propósito del mismo: «Queremos fundar un periódico que sirva de punto de reposo, de campo neutral a los que luchan; un periódico que sea eco de todos los sentimientos nobles y honrados y defensor de todos los intereses legítimos; que no lo vea todo obscuro por ser de la oposición, ni todo claro y risueño por ser ministerial; que acepte lo bueno, lo bello, lo patriótico, lo útil donde quiera que lo halle; que diga la verdad sin pasión, sin soberbia, con modestia, con educación, pero con dignidad y entereza» (pág. 809). Igualmente señala que la empresa que publica La Gaceta Popular «carece de compromisos políticos: los individuos que la constituyen no han vivido ni vivirán jamás del presupuesto ni de la política» (pág. 809). La Gaceta Popular aportó al periodismo de la época algunas novedades. Así, por ejemplo, las noticias se organizaron temáticamente por grupos especiales -religión, política, ciencia, literatura, bellas artes, industria, comercio, finanzas, agricultura, etc.- y como la guerra civil estaba en un periodo álgido la redacción incluyó dos secciones especiales: Noticias de origen liberal y Noticias de origen carlista, demostrando de esta forma la esencial imparcialidad del diario. También subraya como otra aportación novedosa del periódico la inclusión de reseñas financieras, sección que recaía en Fernando Santoyo. Nombela incluye en esta ocasión más datos de los habituales al hablar 
del precio del periódico ${ }^{15}$, colaboradores y secciones del mismo ${ }^{16}$, pues sin duda se trata del proyecto periodístico del que se siente más orgulloso de su dilatada trayectoria profesional. La Gaceta Popular desaparece a consecuencia de la suspensión de la libertad de prensa decretada por el presidente de la República, Emilio Castelar, pues los lectores renunciaron a comprar unos diarios que no les ofrecían las noticias que esperaban. Las tiradas que hasta aquel momento fluctuaban entre 24.000 y 26.000 ejemplares se redujeron a 4000 o 5000 . Nombela siempre medroso ante los problemas financieros no se arriesga a endeudarse y mantener el periódico en circulación.

El escritor subraya que la imparcialidad que asumió al hacerse cargo de $L a$ Gaceta Popular no le impidió identificarse paulatinamente con la causa carlista hasta tomar parte activa en la misma ${ }^{17}$, experiencia política de la que más tarde se arrepentirá y que describe pormenorizadamente en el Libro VI de sus Impresiones y Recuerdos y en el titulado Detrás de las trincheras (1876). Nombela contribuyó a la difusión del partido tradicionalista a través del semanario La Margarita, los libros La bandera española y Dios, patria y el rey que escribe en colaboración con Juan Cancio Mena y los Romanceros de don Carlos.

En 1876, tras su periodo de actividad política, Nombela lleva a cabo nuevos proyectos editoriales que por distintas circunstancias no alcanzarán el éxito espe-

${ }^{15}$ El precio de la suscripción era de cuatro reales al mes en Madrid, cinco en provincias, y el de los números sueltos dos cuartos cada uno.

${ }^{16}$ Nombela ofrece los siguientes datos: «Para redactar el primer artículo, que debía de aparecer con el título de Actualidades, alternaríamos José Fernández Bremón y yo. Francisco Muñoz, hábil e irónico periodista, se encargaría de la Comedia política [...] y en calidad de confeccionador o redactor jefe, como se diría ahora, figuraría Manuel Ossorio y Bernard [...] El folletón de la primera página publicaría: los lunes, Madrid humorístico, por el inolvidable Manuel Matoses (Corzuelo); los martes, Ecos de Europa; los miércoles, Revistas bibliográficas o de vulgarización científica; los jueves, Cuadros y tipos, por Miguel Ramos Carrión; los viernes, Revistas de tribunales [...] los sábados, Murmuraciones, artículos de sabrosa y discreta crítica por Ricardo Sepúlveda [...] y los domingos, Revistas de toros, por Martín Melgar, o de Bellas Artes, por Viñas y Deza, seudónimo que acreditó como literato a quien después como jurisconsulto ha convertido su verdadero nombre, don Luis Díaz Cobeña, en una gloria del foro español» (pág. 811). Asimismo señala que también colaboraron en la Gaceta Popular Conrado Solsona, Castillo y Soriano, el doctor Bora, el ingeniero agrícola Álvarez Alvistur y Fernando Santoyo.

${ }^{17}$ Nombela reconoce en estás páginas que la forma ideal de gobierno de los pueblos activos, vigorosos, ilustrados, justos y liberales es la República. Sin embargo las circunstancias de nuestro atrasado país impide que la República se consolide. Dadas las circunstancias de España la Monarquía se impone y Nombela señala que «El carlismo era la única incógnita que quedaba por despejar; invocaba la tradición, y no la de las monarquías de las casas de Austria y de Borbón, sino la antigua genuinamente española, que en punto de libertades y franquicias no había sido superada, ni siquiera igualada por la Revolución francesa» (pág. 792) 
rado. Nombela publica una revista semanal de carácter enciclopédico similar al Courrier du Dimanche que en París gozaba de gran éxito. Una revista destinada a ofrecer a sus lectores el resumen semanal de lo acontecido en las esferas política, económica y social. Durante el mes de enero de 1876 preparó la propaganda y el día 6 de febrero de este año apareció el primer número de La Semana que «fue considerado por los del oficio como un modelo de confección» (pág. 977). Constaba de cuatro páginas y en ellas, bajo el título de semanas religiosa, política, científica, literaria, teatral, artística, agrícola, industrial, comercial, financiera, etc. los escritores especialistas en estos temas informaban a los lectores de cuanto podía interesarles. A pesar de su novedad y de que la suscripción tenía un coste de dos pesetas al trimestre Nombela reconoce que tuvo que poner término a la misma después de publicar el tercer número por falta de suscripciones. Menor fortuna si cabe tuvo con el Diario de las Familias ${ }^{18}$, El Cascabel ${ }^{10}$, La Gaceta Universal $^{20}$, La Gaceta Agrícola ${ }^{21}$, Biblioteca Pública ${ }^{22}$ y El Teatro ${ }^{23}$.

El fracaso se torna éxito cuando Nombela, aprovechando la agencia telegráfica que acaba de fundar Nilo Fabra, se adelanta a sus competidores y crea la

is Nombela llevó a cabo el proyecto de incluir en la edición de la mañana de La Correspondencia un pequeño diario de amenidad denominado Diario de las Familias. El 23 de enero de 1876 salió el primer ejemplar y su éxito fue superior a lo que su propietario, Manuel María Santana, y el propio Nombela pudieron imaginar, pues a finales de febrero ya contaban con más de seis mil suscriptores. En este caso son cuestiones de tipo económico lo que alejan a Nombela de su proyecto.

${ }^{19}$ En febrero de 1876 Nombela adquiere la popular revista de Carlos Frontaura, El Cascabel. Sin embargo el cambio de propiedad afectó al contenido de la revista y los suscriptores disminuyeron. En abril de 1877 resuelve poner término a la publicación.

${ }^{20}$ Nombela entusiasmado con los deseos del Alfonso XII de transformar España en una nación moderna, vuelve al periodismo político con La Gaceta Universal. Sin embargo, pronto Nombela se alejaría de este nuevo proyecto por desavenencias ideológicas con el resto de propietarios.

${ }^{2}$ Nombela comenta en estas páginas cómo a mediados de 1877 participa en un concurso público para convertirse en editor de la Gaceta Agrícola, una publicación cuyo fin era divulgar entre los agricultores españoles los progresos realizados en la explotación de la tierra. Nombela denuncia que el concurso patrocinado por el ministerio de Fomento estaba amañado y el candidato apoyado por el conde de Toreno, ministro de Fomento, y por el director de Instrucción Pública, de José Cárdenas, obtuvo, finalmente, la explotación de La Gaceta Agricola (1004-1006).

${ }^{22}$ Con la publicación de la Biblioteca Popular Nombela se proponía vulgarizar los conocimientos útiles de forma amena e interesante. Sin embargo el proyecto no se materializó por falta de suscriptores.

${ }^{23}$ Nombela no ofrece datos sobre esta nueva publicación. Sólo señala que se trataba de una revista mensual que informaba a los actores y espectadores de todo cuanto se relacionaba con las representaciones escénicas. Cada número constaba de un cuaderno de sesenta y cuatro páginas en las que se incluía ilustraciones y cuyo precio era de una peseta. 
Agencia literaria internacional. Su novedad radicaba en ofrecer a los periódicos de provincia, a cambio de un módico precio, la posibilidad de insertar artículos que, con el nombre de Ecos de Madrid, ofrecían noticias de «cuanto de interesante y pintoresco ocurría en la Villa y Corte» (pág. 1010). A estos Ecos de Madrid se le unirían más tarde los rotulados Conocimientos útiles y Modas. Negocio editorial que, según Nombela, «llegó a producir de 1.200 a 1.500 pesetas al mes» (1011).

La última y próspera empresa periodística que emprende al comenzar 1888 Julio Nombela es la publicación de una revista dedicada a las mujeres: La Última Moda. La empresa alcanza tanto éxito que el protagonista de estas memorias no duda en calificarla de premio al esfuerzo realizado a lo largo de su vida. La Última Moda produce unos beneficios que no sólo consolidan su publicación a lo largo de más de veinte años, sino que también genera los recursos suficientes para que Nombela monte una imprenta, adquiera máquinas alemanas que imprimen con gran nitidez los grabados y «reunir en un solo edificio de nueva planta los talleres y mi domicilio particular» (pág. 1053). Así, tras cuarenta años de incesante trabajo, de agitada lucha, Nombela logra ese deshago económico y esa vida tranquila que con tanto ahínco ha perseguido.

Nombela, al llegar a la vejez, se siente orgulloso de su trayectoria vital y ofrece la imagen del hombre que desde «la pobreza vergonzante de la clase media a que he pertenecido y pertenezco, he llegado a conseguir el apacible bienestar que ofrece una modesta fortuna, honrada y laboriosamente adquirida» (pág. 12), de ahí que se haya afirmado que Impresiones y Recuerdos encierran la historia de un triunfador (Alberca Serrano, 1993; Gutiérrez Carbajo, 1993). El texto es inequívoco si tenemos en cuenta las manifestaciones explícitas del autor del mismo. Sin embargo no es menos cierto que al lector atento de estas memorias no se le escapa una sensación contraria. Nombela alardea de los esfuerzos realizados y de los logros materiales conseguidos, pero no menciona su satisfacción personal por los frutos de su creación. Enumera títulos de obras escritas o publicadas, pero no muestra orgullo por las figuras que dan vida a las mismas. Así, por ejemplo, se muestra contradictorio a la hora de juzgar lo que sin duda es su mejor obra de creación, las novelas de folletín, pues si por un lado califica su escritura de «labor de pacotilla» (págs. 781), por otro, se niega a dejarlas de escribir cuando se lo exige el director de la Ilustración. La clave naturalmente de esta aparente contradicción estriba en que para Nombela lo económico priva sobre cualquier otra aspiración: «Desde que pude formarme una idea de las dificultades materiales que en la vida nos salen al encuentro, mi afán, mi codicia si se quiere, fue vencerlas [...] experimentaba como una obsesión el deseo de llegar a lo que califica- 
ba mi tierra de promisión; es decir, a tener un hogar en el que no faltase lo indispensable para vivir» (pág. 1034). Significativa es, en este sentido, la comparación que a lo largo de distintos capítulos va estableciendo entre la trayectoria literaria de su buen amigo Gustavo Adolfo Bécquer y la suya propia. La imagen que proyecta de Bécquer corresponde a la de un escritor que no se doblega ante las necesidades económicas, «-No se debe escribir, ni pintar, ni esculpir, ni componer música más que cuando el espíritu siente la necesidad de dar a luz lo que ha creado en sus entrañas -solía decir [Bécquer]» (pág. 341), y fiel a este principio rechazará someterse a la tiranía que impone el periodismo. Nombela, como buen aspirante a la burguesía, lo que le incita a seguir luchando es el deseo de consolidar su posición económica, aunque para ello tenga que escribir unas novelas que sólo serán recordadas por el papel que cumplen en este momento: acrecentar el número de lectores.

En la autobiografía escrita por Nombela tan importantes son los hechos ponderados por el escritor como esas alusiones veladas y los silencios significativos. Así, si tenemos en cuenta estos últimos elementos, más que la autobiografía de un triunfador las Impresiones y recuerdos son la autobiografía de un escritor que renunció en aras del interés material a una carrera literaria de mayor calidad. A Nombela se le escapan en ocasiones velados reproches ante lo que él considera falta de estimación hacia su persona y hacia su trabajo. De hecho confiesa que sólo en dos ocasiones se siente arropado por el calor de periodistas y literatos; la primera, cuando publica en La Época sus Retratos a pluma; la segunda, cuando el Correo de Ultramar, de París, le encarga que busque la colaboración de los escritores españoles de mayor prestigio. Nombela, no obstante, no se engaña por esas muestras de atención que recibe, pues es consciente de que nacen del interés, de ahí que señale que aunque favoreció a muchos escritores -Eusebio Blasco, Javier Ugarte, Fernández Bremón, Castillo y Soriano, Antonio Cortón, Antonio Sánchez Pérez, Fernando Soldevilla, Conrado Solsona, Enrique Sepúlveda-, «de aquel tiempo me quedaron unos cuantos amigos, pocos en verdad» (pág. 1089). Nombela en 1909 se siente solo, olvidado, sin amigos verdaderos, sin haber alcanzado el reconocimiento esperado. De ahí que no dude en utilizar su propio establecimiento editorial - «La Última Moda»-para publicar sus Impresiones y Recuerdos, libro en el que se resaltan, con la clara intencionalidad de que el lector admire su tenacidad y perseverancia, los esfuerzos realizados para salir de la situación económica precaria de la que parte. Nombela pretende confundir al lector, desea proyectar la imagen de un triunfador, pero el lector, como el propio escritor, sabe que el triunfo de un literato no radica en el esfuerzo realizado, sino en el logro alcanzado: «[...] un solo libro, un solo cuadro, una sola sinfonía, más aún, si se quiere, una rima, un boceto, una romanza, bas- 
tan para dar a conocer a un escritor de raza, a un poeta o a un artista de verdadera inspiración» (pág. 341). Un logro artístico que quizás, Nombela, aspira, finalmente, a alcanzar en estas Impresiones y recuerdos.

\section{BIBLIOGRAFÍA CITADA}

ALBERCA SERRANO, Manuel, 1993. «Autobiografía de un triunfador», Cauce, 6, págs. 157-176

AZORÍN. 1998. «Una casa de Madrid», en Obras Escogidas, Madrid, Espasa-Calpe, II, págs. 1046-149.

CABALLÉ, Anna. 1995. Narcisos de tinta, Málaga, Megazul.

DURÁN LÓPEZ, Fernando. 1997. Catálogo comentado de la autobiografía española (Siglos XVIII y XIX), Madrid, Ollero \& Ramos, Editores.

GUTIÉRREZ CARBAJO, Francisco. 1993. «La escritura autobiográfica de Julio Nombela», en Escritura autobiográfica, Madrid, Visor Libros, págs. 233-240.

NOMBELA, Julio, Impresiones y recuerdos, Madrid, Casa editorial «La Última Moda», 1909-1912. [Las citas del texto corresponden a la edición de Jorge Campos, Julio Nombela. Impresiones y Recuerdos, Madrid, Tebas, 1976]. 